\title{
Retention and Fouling during Nanoparticle Filtration: Implications for Membrane Purification of Biotherapeutics
}

\author{
Liang-Kai Chu ${ }^{1}{ }^{\mathbb{D}}$, S. Ranil Wickramasinghe ${ }^{2}$, Xianghong Qian ${ }^{3}$ and Andrew L. Zydney ${ }^{1, * \mathbb{C}}$ \\ 1 Department of Chemical Engineering, The Pennsylvania State University, University Park, PA 16802, USA; \\ 1xc5534@psu.edu \\ 2 Ralph E. Martin Department of Chemical Engineering, University of Arkansas, Fayetteville, AK 72701, USA; \\ swickram@uark.edu \\ 3 Department of Biomedical Engineering, University of Arkansas, Fayetteville, AK 72701, USA; xqian@uark.edu \\ * Correspondence: zydney@engr.psu.edu
}

check for

updates

Citation: Chu, L.-K.

Wickramasinghe, S.R.; Qian, X.;

Zydney, A.L. Retention and Fouling during Nanoparticle Filtration:

Implications for Membrane

Purification of Biotherapeutics.

Membranes 2022, 12, 299.

https://doi.org/10.3390/

membranes12030299

Academic Editor: Jia Wei Chew

Received: 12 February 2022

Accepted: 4 March 2022

Published: 7 March 2022

Publisher's Note: MDPI stays neutral with regard to jurisdictional claims in published maps and institutional affiliations.

Copyright: (c) 2022 by the authors. Licensee MDPI, Basel, Switzerland. This article is an open access article distributed under the terms and conditions of the Creative Commons Attribution (CC BY) license (https:// creativecommons.org/licenses/by/ $4.0 /)$.

\begin{abstract}
One major challenge in the development of nanoparticle-based therapeutics, including viral vectors for the delivery of gene therapies, is the development of cost-effective purification technologies. The objective of this study was to examine fouling and retention behaviors during the filtration of model nanoparticles through membranes of different pore sizes and the effect of solution conditions. Data were obtained with $30 \mathrm{~nm}$ fluorescently labeled polystyrene latex nanoparticles using both cellulosic and polyethersulfone membranes at a constant filtrate flux, and both pressure and nanoparticle transmission were evaluated as a function of cumulative filtrate volume. The addition of $\mathrm{NaCl}$ caused a delay in nanoparticle transmission and an increase in fouling. Nanoparticle transmission was also a function of particle hydrophobicity. These results provide important insights into the factors controlling transmission and fouling during nanoparticle filtration as well as a framework for the development of membrane processes for the purification of nanoparticle-based therapeutics.
\end{abstract}

Keywords: viral vectors; nanoparticles; adeno-associated virus; fouling; hydrophobicity

\section{Introduction}

Recent advances in gene therapy have created renewed interest in the development of biological and synthetic nanoparticle systems for the delivery of RNA and DNA therapeutics. Liposomes and lipid nanoparticles protect nucleic acids from degradation and improve pharmacokinetics [1], forming the basis for mRNA vaccines against COVID-19. Recombinant viral vectors, including both lentivirus [2] and adeno-associated virus (AAV) [3], provide high transfection levels to effectively deliver mRNA and DNA to specific target organs [4]. In addition, nanoparticles can be used to treat solid tumors, e.g., through the generation of hydroxyl radicals that inhibit tumor growth [5].

One challenge in the development of nanoparticle-based therapeutics is the development of effective purification schemes. This includes ensuring sterility of the final product. Frequently, low yields are reported during filtration through sterilizing-grade membranes [6,7]. There is also a need to separate empty from full (DNA- and RNAcontaining) capsids [8-10], which have similar physical characteristics.

Density gradient centrifugation allows for the effective purification of viral capsids on a small scale, but this technique is difficult to apply for large-scale processing [11]. Size-exclusion (SEC) and ion-exchange (IEX) chromatography have both been explored for virus purification, but the large size of the nanoparticles leads to low binding capacities and significant mass transfer limitations $[12,13]$.

Thus, there is much interest in the potential for using membrane technology specifically targeted at the purification of nanoparticle-based therapeutics. Arunkumar and 
Singh [14] examined the use of tangential flow ultrafiltration (TFF) for the final concentration and formulation (buffer exchange) of an AAV product and obtained good results using a $30 \mathrm{kDa}$ nominal molecular weight cutoff composite regenerated cellulose membrane. Peixoto et al. [15] examined the potential of a fully membrane-based downstream process for adenovirus purification. Initial clarification was performed using normal flow filtration through a $0.8 \mu \mathrm{m}$ prefilter and a $0.45 \mu \mathrm{m}$ membrane with the clarified harvest concentrated by TFF. This was followed by an anion-exchange membrane adsorber and then final concentration and formulation by ultrafiltration (UF). The best performance for the TFF was obtained using a $300 \mathrm{kDa}$ polysulfone membrane, as the larger molecular weight cutoff (500 and $750 \mathrm{kDa}$ ) membranes showed inadequate adenovirus retention.

In addition to these studies of viral vector purification, a number of investigators have looked at the ultrafiltration of model nanoparticles that may be significant environmental toxins. For example, Le Hir et al. [16] evaluated the effects of salinity and polydispersity on the ultrafiltration of small $(1.5$ and $10 \mathrm{~nm})$ nanoparticles and noted significant effects of intermolecular interactions between the nanoparticles and with the membrane. Jassby et al. [17] examined the filtration of C60 fullerenes in the presence of different salts, showing that the addition of divalent cations led to the formation of large aggregates that were more highly retained by a ceramic membrane.

Despite these previous efforts, there is still little fundamental information on the factors controlling nanoparticle filtration. The objective of this study was to evaluate the retention and fouling behavior of $30 \mathrm{~nm}$ polystyrene nanoparticle suspensions as a model for an AAV biotherapeutic. Data were obtained over a range of solution conductivities and surfactant concentrations for nanoparticles with different surface charge and hydrophobicity using both cellulosic and polyethersulfone membranes, the two most widely used polymeric membranes in bioprocessing [18]. Our results provide important insights into the factors controlling nanoparticle filtration, providing a framework for future studies of membrane systems for the purification of nanoparticle-based biotherapeutics.

\section{Materials and Methods}

\subsection{Nanoparticle Feed Solution Preparation}

Data were obtained with $30 \mathrm{~nm}$ fluorescently labeled polystyrene latex nanoparticles from MagSphere (Pasadena, CA, USA) as a model for AAV (reported size of 25-28 nm [19,20]). Three different nanoparticles were examined with different dyes (blue, red, and orange); these nanoparticles had similar size but different hydrophobicity, as discussed in the Results. Nanoparticles were suspended at a concentration of approximately $3.4 \times 10^{12}$ particles $/ \mathrm{mL}$ in $10 \mathrm{mM}$ Tris buffer prepared from a $1 \mathrm{M}$ Tris stock solution (Invitrogen, Waltham, MA, USA) using deionized (DI) water from a Millipore Direct-Q purification unit (Burlington, MA, USA). Solution $\mathrm{pH}$ was adjusted to 7.5 using $1 \mathrm{M} \mathrm{HCl}$. Tween 20 (0.01 weight percent) (Sigma, St. Louis, MO, USA) was added to minimize particle aggregation. Conductivity was adjusted by addition of $\mathrm{NaCl}$ (RND Center, La Jolla, CA, USA).

The particle size distribution and zeta potential were evaluated using a Zetasizer Nano ZS90 (Malvern Panalytical, Westborough, MA, USA). Samples were prepared in $10 \mathrm{mM}$ Tris buffer with $0.01 \%$ Tween 20 without sonication. The light-scattering intensity was measured for three repeat scans at room temperature. The particle size was determined from the measured diffusivity based on the Stokes-Einstein equation, while the zeta potential was determined from the measured electrophoretic mobility.

\subsection{Modified Hydrophobic Interaction Chromatography}

Nanoparticle hydrophobicity was evaluated using the membrane hydrophobic interaction chromatography (MHIC) protocol developed by Taylor et al. [21]. Nanoparticle retention was determined using a $5 \mu \mathrm{m}$ pore size polyvinylidene fluoride (PVDF) Durapore membrane from MilliporeSigma (Burlington, MA, USA) as the solid phase. The membrane was initially equilibrated in $2 \mathrm{M}$ ammonium sulfate, $50 \mathrm{mM}$ phosphate buffer at a flow rate of $4 \mathrm{~mL} / \mathrm{min}$ (corresponding to a linear velocity of $0.32 \mathrm{~mm} / \mathrm{s}$ ) set using an AKTA 
150 fast protein liquid chromatography (FPLC) system (Cytiva, Marlborough, MA, USA). A $1 \mathrm{~mL}$ nanoparticle suspension was injected, and nanoparticle elution was evaluated using a linear gradient between the equilibration buffer and a $5 \mathrm{mM}$ phosphate buffer (from $0 \%$ to $100 \%$ phosphate buffer) over $15 \mathrm{~min}$. The nanoparticle concentration was determined by UV absorbance at $280 \mathrm{~nm}$.

\subsection{Nanoparticle Filtration}

Filtration experiments were performed with $0.1 \mu \mathrm{m}$ pore size mixed cellulose ester microfiltration membranes; 100 and $300 \mathrm{kDa}$ nominal molecular weight cutoff Ultracel composite regenerated cellulose ultrafiltration membranes; and 100, 300, and $500 \mathrm{kDa}$ Biomax polyethersulfone membranes, all provided by MilliporeSigma (Burlington, MA, USA). Cellulosic and polyethersulfone membranes are widely used in bioprocessing for the purification of recombinant proteins, monoclonal antibodies, and vaccines [18]. Cellulosic membranes are highly hydrophilic (with contact angle $<20^{\circ}$ ), while polyethersulfone membranes are somewhat more hydrophobic (contact angle of $56^{\circ}$ [22]). The mixed cellulose ester membrane was simply flushed with DI water to remove any storage or wetting agents, while the Ultracel and Biomax membranes were first soaked in isopropyl alcohol (IPA) before flushing. Membranes were cut into $25 \mathrm{~mm}$ diameter discs and placed in the base of a stainless steel holder (Pall, New York, NY, USA).

The nanoparticle suspension was fed to the filtration unit using a Masterflex peristaltic pump (Cole-Parmer, Vernon Hill, IL, USA) operated at a filtrate flow rate of $0.93 \mathrm{~mL} / \mathrm{min}$, providing a filtrate flux of $150 \mathrm{~L} / \mathrm{m}^{2} / \mathrm{h}(\mathrm{LMH})$. PTFE tubing was used for all connections to minimize particle adhesion and loss. Transmembrane pressure was evaluated using a digital pressure gauge (Ashcroft, Stratford, CT, USA) placed immediately upstream of the stainless steel holder.

Permeate samples were obtained every five minutes over the first twenty minutes and then every ten minutes until the end of the filtration. Nanoparticle concentrations were measured in duplicate based on the fluorescence intensity evaluated using 96-well Fisher black-bottom plates placed in a Tecan Infinite 200 microplate reader (Hombrechtikon, Switzerland). The fluorescence intensity was highly linear over the full range of particle concentrations with $\mathrm{R}^{2}>0.99$.

\section{Results and Discussion}

\subsection{Nanoparticle Characterization}

Figure 1 shows the size distribution of the suspension of blue nanoparticles obtained by dynamic light scattering (DLS). The suspension was monodisperse with a Z-average size of $34 \mathrm{~nm}$ and a range from 15 to approximately $80 \mathrm{~nm}$. Similar results were obtained with the orange and red nanoparticles (Z-average size provided in Table 1). The measured size was slightly larger than that provided by the manufacturer $(28-30 \mathrm{~nm})$ but was consistent with limited SEM images (Figure S1). There was no evidence of any nanoparticle aggregation. The measured size was similar to the range reported for AAV [19,20]. The nanoparticles were all negatively charged; the measured zeta potentials were around $-15 \mathrm{mV}$ for the blue, orange, and red nanoparticles, as summarized in Table 1.

Table 1. Physical properties of different nanoparticles used in this study.

\begin{tabular}{ccccc}
\hline & Emission Wavelength & Z-Average Diameter & Zeta Potential & MHIC Retention \\
\hline Blue & $419 \mathrm{~nm}$ & $34 \pm 2 \mathrm{~nm}$ & $-15 \pm 1 \mathrm{mV}$ & $2 / 8 / 13 \mathrm{~min}$ \\
\hline Orange & $614 \mathrm{~nm}$ & $35 \pm 1 \mathrm{~nm}$ & $-15 \pm 1 \mathrm{mV}$ & $13 \mathrm{~min}$ \\
\hline Red & $630 \mathrm{~nm}$ & $35 \pm 1 \mathrm{~nm}$ & $-14 \pm 1 \mathrm{mV}$ & ND \\
\hline
\end{tabular}




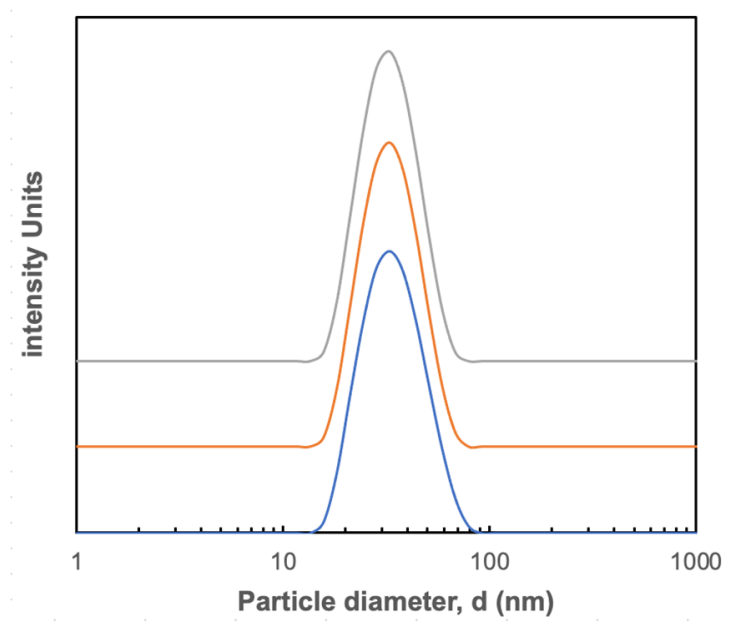

Figure 1. Intensity distribution of blue polystyrene nanoparticles determined using dynamic light scattering. Different color curves are shown for 3 repeat measurements with the y-axis displaced to improve clarity.

The surface hydrophobicity of the polystyrene nanoparticles was determined by membrane hydrophobic interaction chromatography using a $5 \mu \mathrm{m}$ pore size PVDF membrane as the solid phase. Typical results are shown in Figure 2 for the blue and orange nanoparticles in response to a linear gradient between $2 \mathrm{M}$ ammonium sulfate with $50 \mathrm{mM}$ phosphate and $2 \mathrm{M}$ ammonium sulfate with $5 \mathrm{mM}$ phosphate, both with $0.01 \%$ Tween 20 . The blue particles showed three distinct peaks: a larger peak at $8 \mathrm{~min}$ (corresponding to approximately $60 \%$ of the $5 \mathrm{mM}$ phosphate buffer) and smaller peaks at 2 and $13 \mathrm{~min}$. In contrast, the orange nanoparticles showed only a single peak at 13 min near the end of the gradient, i.e., at a greater percentage of phosphate for elution. This indicated that the orange nanoparticles were significantly more hydrophobic than the blue nanoparticles. These differences in hydrophobicity were likely related to the properties of the fluorescent dyes used to label the different nanoparticles.

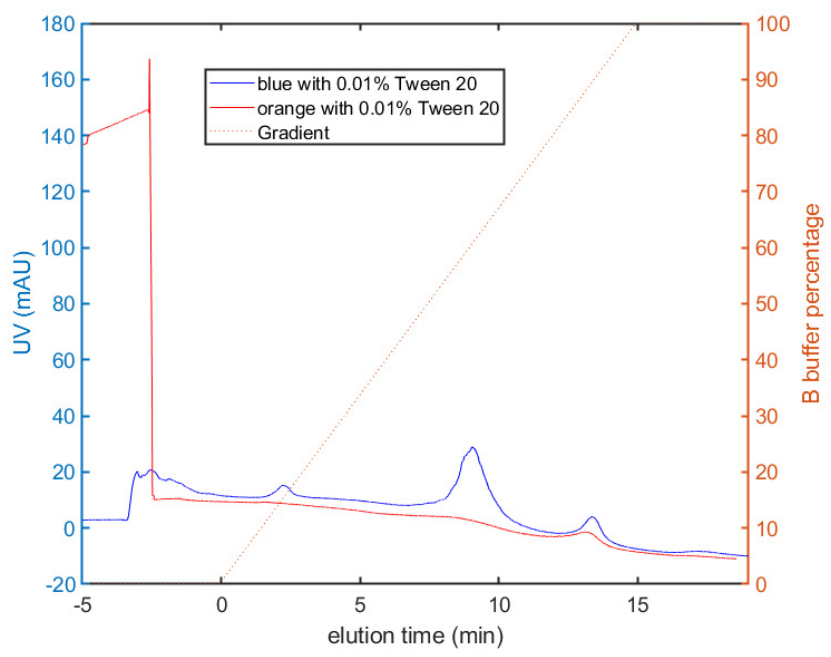

Figure 2. Membrane hydrophobic interaction chromatography for orange and blue nanoparticles.

\subsection{Nanoparticle Filtration}

The cellulosic membranes of different pore sizes were challenged with the $30 \mathrm{~nm}$ blue polystyrene nanoparticles at a constant flux of $150 \mathrm{LMH}$, with the data for transmembrane pressure (TMP) and nanoparticle transmission as a function of the volumetric throughput shown in the bottom and top panels of Figure 3, respectively. The data were highly reproducible, as repeat experiments showed nearly identical behavior with $<10 \%$ differences in 
both the TMP and transmission. Both the Ultracel 100 and 300 membranes showed rapid fouling, with pressure exceeding $20 \mathrm{psi}(140 \mathrm{kPa})$ after approximately 25 and $50 \mathrm{~L} / \mathrm{m}^{2}$, respectively. The nanoparticle transmission, defined as the ratio of the nanoparticle concentration in the permeate samples to that in the feed, was evaluated as:

$$
T=\frac{I_{\text {permeate }}}{I_{\text {feed }}}
$$

where $I_{\text {permeate }}$ and $I_{\text {feed }}$ are the fluorescence intensities in the permeate and feed samples, respectively. The nanoparticle transmission for the Ultracel 100 and 300 membranes remained below $10 \%$ over the course of the filtration, which was consistent with the small effective pore size of these membranes (see Table 2). In contrast, the $0.1 \mu \mathrm{m}$ mixed cellulose ester membrane had $>70 \%$ particle transmission, and the transmembrane pressure stabilized at approximately 4 psi. The increase in nanoparticle concentration in the permeate samples over the first $20 \mathrm{~L} / \mathrm{m}^{2}$ was likely due, in part, to dilution effects associated with the hold-up volume within the membrane and module, although there may also have been a low level of nanoparticle retention during the initial stage of the filtration. There was no evidence of any selective retention of the nanoparticles by the $0.1 \mu \mathrm{m}$ mixed cellulose ester membrane; the mean size of the nanoparticles in the permeate samples was statistically identical to that for the feed based on DLS.
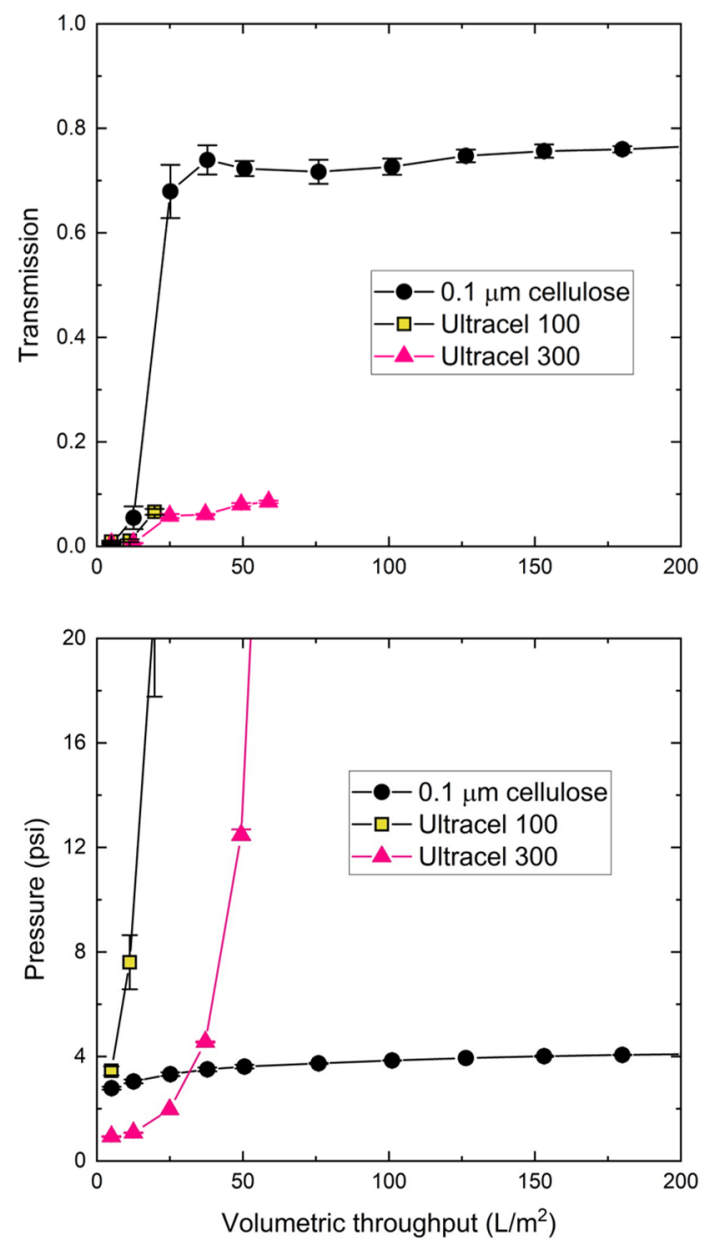

Figure 3. Particle transmission (top panel) and transmembrane pressure (bottom panel) during filtration of $30 \mathrm{~nm}$ blue polystyrene nanoparticles through the different cellulosic membranes at a concentration of $3.4 \times 10^{12}$ particles $/ \mathrm{mL}$ in $10 \mathrm{mM}$ Tris buffer with $0.01 \%$ Tween 20 at a constant filtrate flux of $150 \mathrm{LMH}$. Error bars represent the standard deviation for repeat measurements (not shown when smaller than the size of the symbol). 
Table 2. Pore size, throughput (evaluated at TMP = $10 \mathrm{psi}$ ), and average transmission for $0.1 \mu \mathrm{m}$ mixed cellulose ester, Ultracel, and Biomax membranes.

\begin{tabular}{ccccccc}
\hline & $\mathbf{0 . 1} \boldsymbol{\mu m}$ & Biomax 100 & Biomax 300 & Biomax 500 & Ultracel 100 & Ultracel 300 \\
\hline $\begin{array}{c}\text { Pore diameter } \\
d_{p}(\mathrm{~nm})\end{array}$ & 100 & $13 \pm 1$ & $18 \pm 1$ & $32 \pm 2$ & $9.0 \pm 0.2$ & $20 \pm 1$ \\
\hline $\begin{array}{c}\text { Throughput at } \\
10 \mathrm{psi}\left(\mathrm{L} / \mathrm{m}^{2}\right)\end{array}$ & $>200$ & 23 & 24 & $>200$ & 13 & 46 \\
\hline $\begin{array}{c}\text { Average } \\
\text { Transmission }\end{array}$ & $74 \%$ & $5 \%$ & $13 \%$ & $79 \%$ & $5 \%$ \\
\hline
\end{tabular}

Table 2 summarizes the results for the Ultracel, Biomax, and mixed cellulose ester membranes challenged with the blue nanoparticle suspensions in $10 \mathrm{mM}$ Tris buffer at a $\mathrm{pH}$ of 7.5. The pore diameters $\left(d_{p}\right)$ for the ultrafiltration membranes were calculated from the measured hydraulic permeabilities $\left(L_{p}\right)$ of the membranes as [23]:

$$
d_{p}=\left(\frac{32 \mu \delta_{m} L_{p}}{\varepsilon}\right)^{1 / 2}
$$

where $\mu$ is the solution viscosity, $\delta_{m}$ is the thickness of the membrane skin (taken as $1 \mu \mathrm{m}$ ), and $\varepsilon$ is the membrane porosity. Equation (2) may underestimate pore size, particularly for the Biomax $500 \mathrm{kDa}$ membrane, as it does not account for the resistance of the membrane substructure. The 100 and $300 \mathrm{kDa}$ nominal molecular weight cutoff membranes fouled rapidly with very low nanoparticle transmission, which was consistent with the small pore size of these membranes. The results for the Ultracel (cellulose) and Biomax (polyethersulfone) membranes were similar, despite differences in polymer chemistry. The $0.1 \mu \mathrm{m}$ mixed cellulose ester and Biomax 500 membranes had relatively little fouling with more than $70 \%$ nanoparticle transmission (evaluated over the entire filtration experiment). In addition, the transmembrane pressure remained below 5 psi up to $200 \mathrm{~L} / \mathrm{m}^{2}$.

\subsection{Buffer Effects}

Figure 4 examines the effects of buffer conductivity, adjusted by the addition of $\mathrm{NaCl}$, on the TMP and nanoparticle transmission through the $0.1 \mu \mathrm{m}$ mixed cellulose ester membrane. The transmission increased rapidly for the solution without any added $\mathrm{NaCl}$, attaining a value above $70 \%$ after only $30 \mathrm{~L} / \mathrm{m}^{2}$. Similar profiles were obtained in the presence of 10,50, and $200 \mathrm{mM} \mathrm{NaCl}$, while the data for the higher $\mathrm{NaCl}$ solutions showed a delay in the rise in transmission. This effect was quite pronounced for the $200 \mathrm{mM} \mathrm{NaCl}$ solution, as the transmission remained below $6 \%$ over the first $50 \mathrm{~L} / \mathrm{m}^{2}$ and then rapidly increased to approximately $70 \%$. This time lag was likely due to nanoparticles binding to the filter in the higher ionic strength solutions, which was consistent with the greater increase in transmembrane pressure (bottom panel). The steady-state transmission at high throughput may reflect the saturation of the binding sites within the membrane. The behavior in the presence of $500 \mathrm{mM} \mathrm{NaCl}$ was quite different. In both repeat experiments, the nanoparticle transmission passed through a maximum before declining at high throughput. In addition, the TMP showed an intermediate plateau followed by a rapid increase to more than $15 \mathrm{psi}$. This may have reflected the formation of a particle cake on or within the $0.1 \mu \mathrm{m}$ mixed cellulose ester membrane, which served as a dynamic membrane that was able to retain the nanoparticles in the feed.

The effect of nanoparticle hydrophobicity on filtration behavior is examined in Figure 5, which shows data for the filtration of the blue, orange, and red nanoparticles through separate $0.1 \mu \mathrm{m}$ mixed cellulose ester membranes. In contrast to the blue nanoparticles, which showed nearly $80 \%$ transmission, the orange and red nanoparticles showed a maximum transmission of only $10 \%$, even though the TMP remained below 5 psi up until $200 \mathrm{~L} / \mathrm{m}^{2}$. This is very different than the behavior observed with the 100 and $300 \mathrm{kDa}$ Ultracel membranes, which retained the nanoparticles due to their small pore size. Instead, the low 
transmission of the orange and red nanoparticles by the $0.1 \mu \mathrm{m}$ pore size membrane was likely due to hydrophobic interactions, which is consistent with the greater hydrophobicity (retention time) evaluated in the MHIC analysis (Table 1).
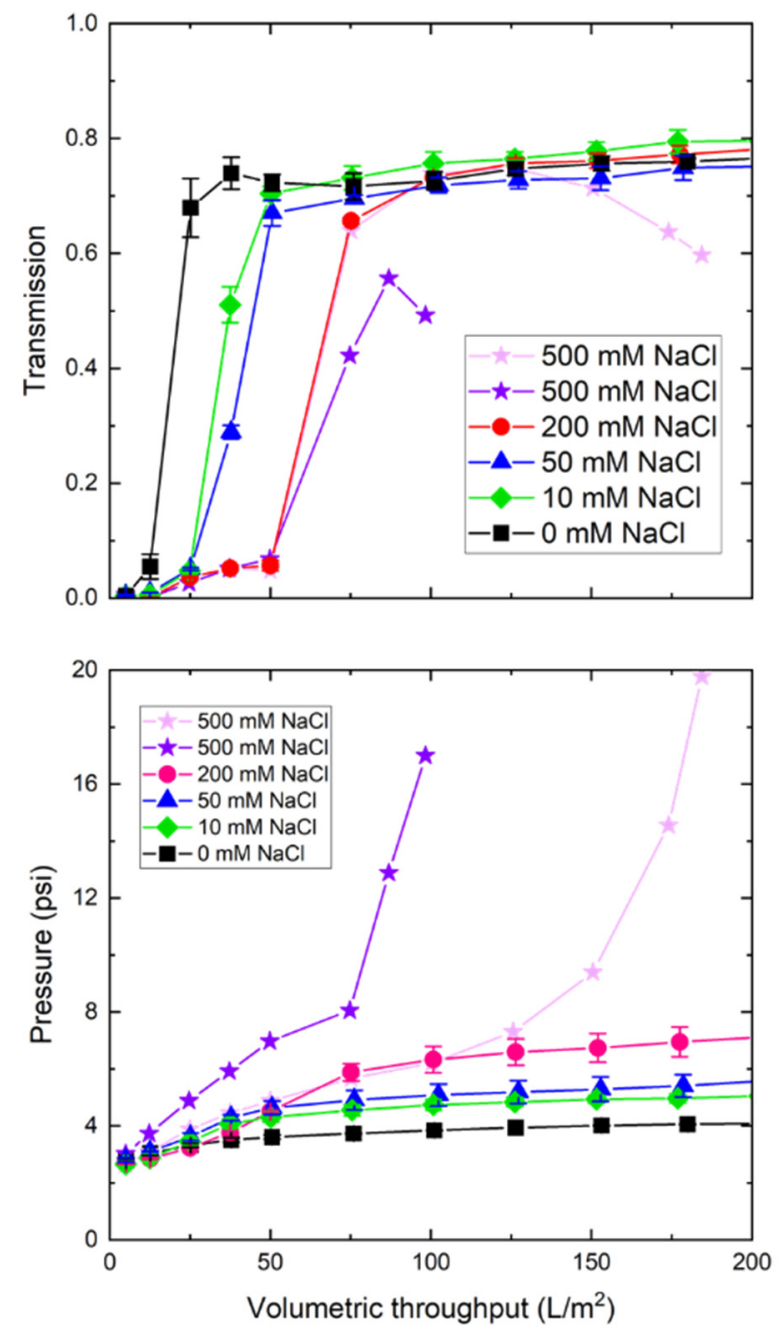

Figure 4. Nanoparticle transmission (top panel) and transmembrane pressure (bottom panel) during filtration of the $30 \mathrm{~nm}$ blue polystyrene nanoparticles through $0.1 \mu \mathrm{m}$ mixed cellulose ester membranes in the presence of added $\mathrm{NaCl}$ at a constant filtrate flux of $150 \mathrm{LMH}$.

To confirm that the behavior seen in Figure 5 was not due to differences in the membranes used in the different experiments, data were obtained with a binary mixture of the blue and orange nanoparticles using the Biomax $500 \mathrm{kDa}$ membrane (Figure S2). The nanoparticle transmission data for the binary mixture were nearly identical to those obtained with suspensions of the individual nanoparticles, as there was high transmission of the more hydrophilic blue nanoparticles and high retention of the more hydrophobic orange nanoparticles. The transmembrane pressure increased somewhat more rapidly during filtration of the binary mixture, which may reflect some degree of particle-particle interactions with the more hydrophobic polyethersulfone membrane, or it may simply reflect the inherent run-to-run variability.

Additional insights into the effects of hydrophobic interactions on nanoparticle transmission were obtained by performing a series of experiments with the very hydrophobic orange particles in the presence of different amounts of Tween 20. The addition of small amounts of Tween 20 caused a small increase in nanoparticle transmission, from $<4 \%$ to approximately $8 \%$ as the Tween 20 concentration increased from $0 \%$ to $0.01 \%$ (Figure 6). However, the nanoparticle transmission in the presence of $0.05 \%$ Tween 20 remained below 
$4 \%$ throughout the experiment, and the TMP increased rapidly, providing a maximum capacity of $<100 \mathrm{~L} / \mathrm{m}^{2}$. This was unlikely to be due to micelle formation as the critical micelle concentration for Tween 20 is reported as being between $0.06 \%$ and $0.07 \%$ [24]. In addition, this rapid increase in TMP was not seen when $0.05 \%$ Tween 20 was added to the less hydrophobic blue nanoparticles (Figure S3). Instead, the addition of Tween 20 may have been facilitating the aggregation and association of the more hydrophobic nanoparticles. Future studies are required to quantify this phenomenon.
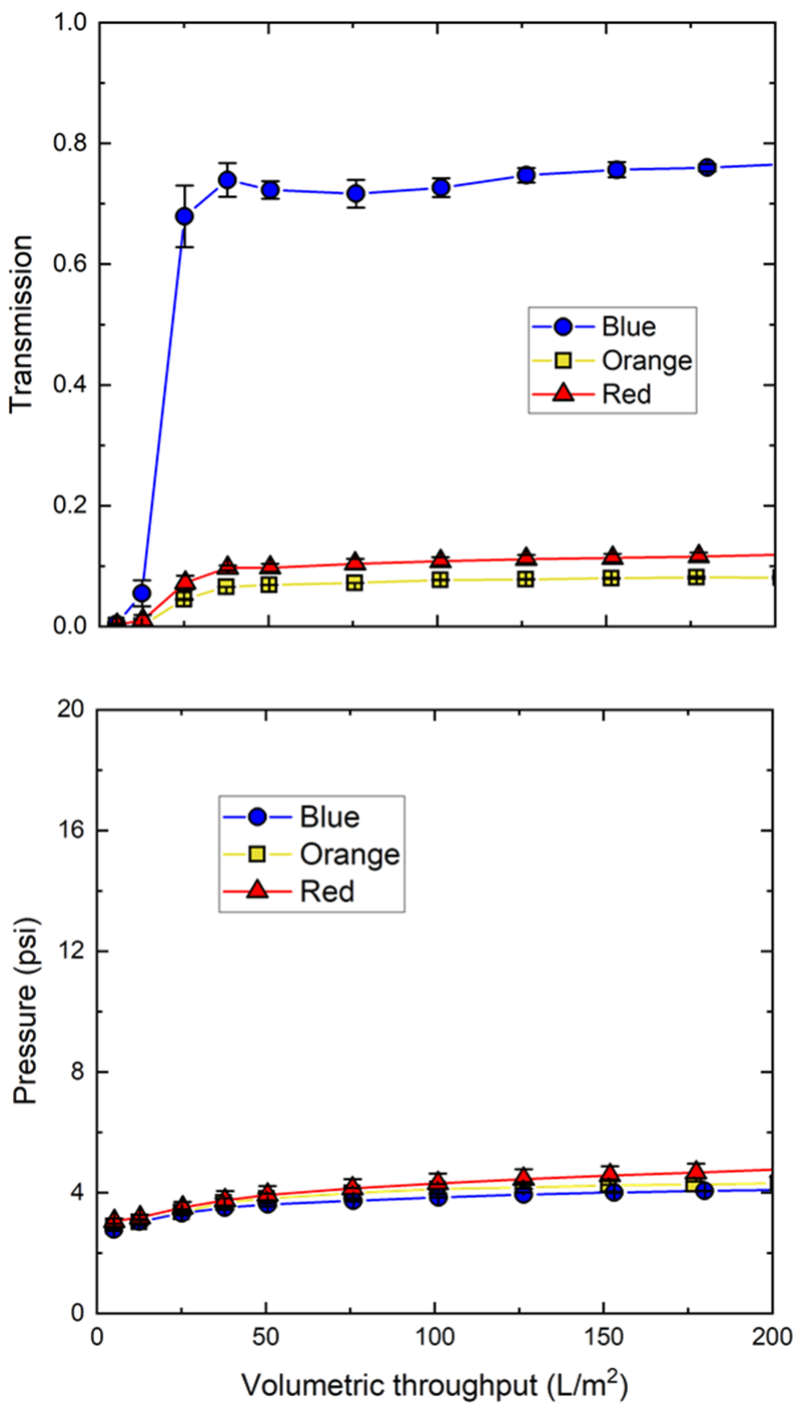

Figure 5. Particle transmission (top panel) and transmembrane pressure (bottom panel) for the different $30 \mathrm{~nm}$ polystyrene nanoparticles during filtration through $0.1 \mu \mathrm{m}$ mixed cellulose ester membranes at a constant filtrate flux of $150 \mathrm{LMH}$. Data obtained with suspensions containing $3.4 \times 10^{12}$ particles $/ \mathrm{mL}$ in $10 \mathrm{mM}$ Tris buffer with $0.01 \%$ Tween 20 . 

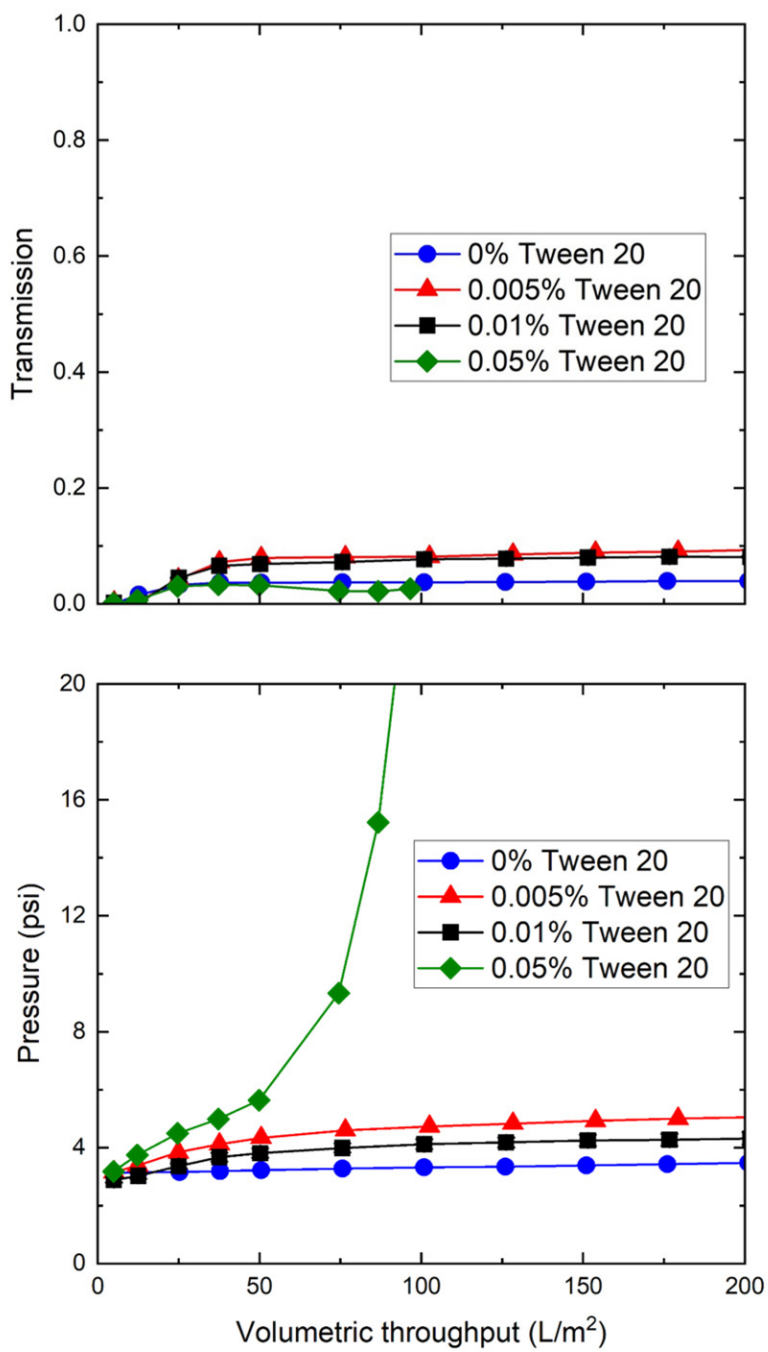

Figure 6. Effect of Tween 20 on nanoparticle transmission (top panel) and transmembrane pressure (bottom panel) during filtration of the $30 \mathrm{~nm}$ orange polystyrene nanoparticles through $0.1 \mu \mathrm{m}$ mixed cellulose ester membranes at a constant filtrate flux of $150 \mathrm{LMH}$. Data obtained with suspensions having $3.4 \times 10^{12}$ particles $/ \mathrm{mL}$ in $10 \mathrm{mM}$ Tris buffer.

\section{Conclusions}

This paper examined the effects of solution conditions and nanoparticle hydrophobicity on the filtration of $30 \mathrm{~nm}$ polystyrene nanoparticles through both cellulosic (highly hydrophilic) and polyethersulfone membranes. High nanoparticle transmission was obtained with both a $0.1 \mu \mathrm{m}$ mixed cellulose ester membrane and a $500 \mathrm{kDa}$ Biomax polyethersulfone membrane; both the 100 and $300 \mathrm{kDa}$ Ultracel and Biomax membranes had high particle retention due to their small pore size, despite their difference in hydrophobicity. The addition of $\mathrm{NaCl}$ caused a delay in nanoparticle transmission through the $0.1 \mu \mathrm{m}$ mixed cellulose ester membrane, while the use of $500 \mathrm{mM} \mathrm{NaCl}$ led to a decrease in transmission at high throughput. The filtration of more hydrophobic nanoparticles led to significantly greater fouling with relatively low nanoparticle transmission. The filtration of actual AAV particles is far more complex due to the variability of biological particles, the presence of a diverse array of impurities, and the need to separate filled from empty and defective capsids. The results obtained in this study provide important insights into the factors controlling nanoparticle retention and fouling, providing an initial framework that may be used to assist the development of membrane filtration systems for the purification of nanoparticle-based therapeutics like AAV. 
Supplementary Materials: The following supporting information can be downloaded at: https: / / www.mdpi.com/article/10.3390/membranes12030299/s1, Figure S1: SEM image of polystyrene nanoparticles; Figure S2: Filtration of blue and orange nanoparticles, alone and in binary mixture, through the Biomax $500 \mathrm{kDa}$ membrane; Figure S3: Effect of Tween 20 on the filtration of $30 \mathrm{~nm}$ blue nanoparticles through the $0.1 \mu \mathrm{m}$ mixed cellulose ester membranes.

Author Contributions: Conceptualization, A.L.Z.; data curation, L.-K.C.; formal analysis, L.-K.C.; funding, A.L.Z.; supervision, A.L.Z.; writing—original draft, L.-K.C.; writing-review and editing, A.L.Z., X.Q. and S.R.W. All authors have read and agreed to the published version of the manuscript.

Funding: This work was supported through the Membrane Science, Engineering, and Technology (MAST) Center and is funded by grant number 1841474 from the NSF IUCRC program.

Institutional Review Board Statement: Not applicable.

Informed Consent Statement: Not applicable.

Data Availability Statement: The data presented in this study are available upon request from the corresponding author.

Acknowledgments: The authors would like to acknowledge helpful discussions with Xiaolei Hao and Ronny Horax at the University of Arkansas.

Conflicts of Interest: The authors declare no conflict of interest.

\section{References}

1. Hou, X.; Zaks, T.; Langer, R.; Dong, Y. Lipid nanoparticles for mRNA delivery. Nat. Rev. Mater. 2021, 6, 1078-1094. [CrossRef]

2. Milone, M.C.; O'Doherty, U. Clinical use of lentiviral vectors. Leukemia 2018, 32, 1529-1542. [CrossRef]

3. Wang, D.; Tai, P.W.L.; Gao, G. Adeno-associated virus vector as a platform for gene therapy delivery. Nat. Rev. Drug Discov. 2019, 18, 358-378. [CrossRef] [PubMed]

4. Begum, A.A.; Toth, I.; Hussein, W.M.; Moyle, P.M. Advances in targeted gene delivery. Curr. Drug Deliv. 2019, 16, 588-608. [CrossRef] [PubMed]

5. Lv, R.; Du, K.; Liu, Q.; Meng, X.; Chen, L.; Wang, Z. Nano iron-copper alloys for tumor ablation: Efficiently amplified oxidative stress through acid response. New J. Chem. 2020, 44, 14438-14446. [CrossRef]

6. Taylor, N.; Ma, W.; Kristopeit, A.; Wang, S.-C.; Zydney, A.L. Enhancing the performance of sterile filtration for viral vaccines and model nanoparticles using an appropriate prefilter. J. Membr. Sci. 2022, 674, 120264. [CrossRef]

7. Bos, G.W.; Trullas-Jimeno, A.; Jiskoot, W.; Crommelin, D.J.A.; Hennink, W.E. Sterilization of poly(dimethylamino) ethyl methacrylate-based gene transfer complexes. Int. J. Pharm. 2000, 211, 79-88. [CrossRef]

8. Wright, J.F. Product-Related Impurities in Clinical-Grade Recombinant AAV Vectors: Characterization and Risk Assessment. Biomedicines 2014, 2, 80-97. [CrossRef] [PubMed]

9. Adams, B.; Bak, H.; Tustian, A.D. Moving from the bench towards a large scale, industrial platform process for adeno-associated viral vector purification. Biotechnol. Bioeng. 2020, 117, 3199-3211. [CrossRef] [PubMed]

10. Gagnon, P.; Leskovec, M.; Prebil, S.D.; Žigon, R.; Štokelj, M.; Raspor, A.; Peljhan, S.; Štrancar, A. Removal of empty capsids from adeno-associated virus preparations by multimodal metal affinity chromatography. J. Chromatogr. A 2021, 1649, 462210. [CrossRef] [PubMed]

11. Reimer, C.B.; Baker, R.S.; Van Frank, R.M.; Newlin, T.E.; Cline, G.B.; Anderson, N.G. Purification of large quantities of influenza virus by density gradient centrifugation. J. Virol. 1967, 1, 1207-1216. [CrossRef]

12. Joshi, P.; Bernier, A.; Moço, P.D.; Schrag, J.; Chahal, P.S.; Kamen, A. Development of a scalable and robust AEX method for enriched rAAV preparations in genome-containing VCs of serotypes 5, 6, 8, and 9. Mol. Ther. Methods Clin. Dev. 2021, 21, 341-356. [CrossRef] [PubMed]

13. Smith, R.H.; Yang, L.; Kotin, R.M. Chromatography-based purification of adeno-associated virus. Methods Mol. Biol. 2008, 434, 37-54. [CrossRef]

14. Arunkumar, A.; Singh, N. Ultrafiltration behavior of recombinant adeno associated viral vectors used in gene therapy. J. Membr. Sci. 2021, 620, 118812. [CrossRef]

15. Peixoto, C.; Ferreira, T.B.; Sousa, M.F.Q.; Carrondo, M.J.T.; Alves, P.M. Towards purification of adenoviral vectors based on membrane technology. Biotechnol. Prog. 2008, 24, 1290-1296. [CrossRef] [PubMed]

16. Le Hir, M.; Wyart, Y.; Georges, G.; Lamoine, L.S.; Sauvade, P.; Moulin, P. Effect of salinity and nanoparticle polydispersity on UF membrane retention fouling. J. Membr. Sci. 2018, 563, 405-418. [CrossRef]

17. Jassby, D.; Chae, S.R.; Hendren, Z.; Wiesner, M. Membrane filtration of fullerene nanoparticle suspensions: Effects of derivatization, pressure, electrolyte species and concentration. J. Colloid Interface Sci. 2010, 346, 296-302. [CrossRef]

18. Van Reis, R.; Zydney, A.L. Bioprocess membrane technology. J. Membr. Sci. 2007, 297, 16-50. [CrossRef] 
19. McIntosh, N.L.; Berguig, G.Y.; Karim, O.A.; Cortesio, C.L.; de Angelis, R.; Khan, A.A.; Gold, D.; Maga, J.A.; Bhat, V.S. Comprehensive characterization and quantification of adeno associated vectors by size exclusion chromatography and multi-angle light scattering. Sci. Rep. 2021, 11, 3012. [CrossRef] [PubMed]

20. Cole, L.; Fernandes, D.; Hussain, M.T.; Kaszuba, M.; Stenson, J.; Markova, N. Characterization of Recombinant Adeno-Associated Viruses (rAAVs) for Gene Therapy Using Orthogonal Techniques. Pharmaceutics 2021, 13, 586. [CrossRef] [PubMed]

21. Taylor, N.; Ma, W.; Kristopeit, A.; Wang, S.C.; Zydney, A.L. Evaluating nanoparticle hydrophobicity using analytical membrane hydrophobic interaction chromatography. Anal. Chem. 2022, Submitted.

22. Shao, J.; Hou, J.; Song, H. Comparison of humic acid rejection and flux decline during filtration with negatively charged and uncharged ultrafiltration membranes. Water Res. 2011, 45, 473-482. [CrossRef] [PubMed]

23. Rao, S.; Zydney, A.L. High resolution protein separations using affinity ultrafiltration with small charged ligands. J. Membr. Sci. 2006, 280, 781-789. [CrossRef]

24. Hait, S.K.; Moulik, S.P. Determination of critical micelle concentration (CMC) of nonionic surfactants by donor-acceptor interaction with lodine and correlation of CMC with hydrophile-lipophile balance and other parameters of the surfactants. J. Surfactants Deterg. 2001, 4, 303-309. [CrossRef] 